\title{
Assessment of the prevalence and characteristics of dens invaginatus in a sample of Turkish Anatolian population
}

\author{
Fatih Cakici ${ }^{1}$, Mevlut Celikoglu ${ }^{2}$, Hakan Arslan ${ }^{1}$, Huseyin-Sinan Topcuoglu ${ }^{1}$, Aziz-Sahin Erdogan ${ }^{3}$ \\ ${ }^{1}$ Research Assistant, Department of Endodontic, Faculty of Dentistry, Ataturk University, Erzurum, Turkey \\ ${ }^{2}$ Research Assistant, Department of Orthodontics, Faculty of Dentistry, Ataturk University, Erzurum, Turkey \\ ${ }^{3}$ Assistant professor, Department of Endodontic, Faculty of Dentistry, Ataturk University, Erzurum, Turkey
}

Correspondence:

Department of Orthodontics

Faculty of Dentistry

Ataturk University

Erzurum, 25240, Turkey

mevlutcelikoglu@hotmail.com

\begin{abstract}
Cakici F, Celikoglu M, Arslan H, Topcuoglu HS, Erdogan AS. Assessment of the prevalence and characteristics of dens invaginatus in a sample of Turkish Anatolian population. Med Oral Patol Oral Cir Bucal. 2010 Nov 1;15 (6):e855-8.

http://www.medicinaoral.com/medoralfree01/v15i6/medoralv15i6p855.pdf
\end{abstract}

Received: 23/10/2009

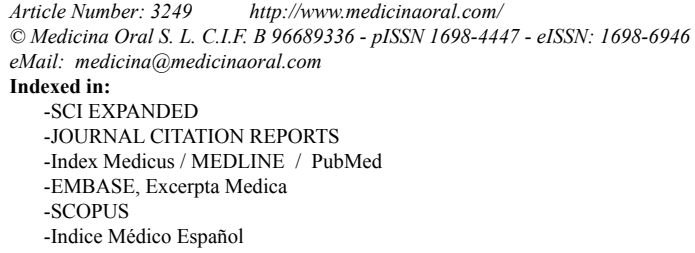

\begin{abstract}
Objective: The objective of this study was to assess the prevalence and characteristics of dens invaginatus in anterior teeth and to classify the type of dens invaginatus in a sample of Turkish Anatolian population.

Study design: A retrospective study was performed using full-mouth periapical and panoramic radiographs of 1012 patients. Maxillary and mandibular anterior teeth were evaluated for the presence and characteristics of dens invaginatus. Statistical evaluation of the presence of dens invaginatus related to gender was performed by the Pearson chi-squared test.

Results: Dens invaginatus was observed in 13 out of 1012 subjects and in only maxillary lateral incisors. There were no periapical lesions in teeth with types I and II, whereas both of the subjects with type III had apical periodontitis at the time of referral. Males and females were almost equally affected by dens invaginatus $(\mathrm{P}=0.98)$. Conclusion: The anomaly was detected in only maxillary lateral incisors with no gender difference and the most commonly observed type of dens invaginatus was type I ( $81.25 \%)$.
\end{abstract}

Key words: Dens invaginatus, developmental abnormalities, dens in dente. 


\section{Introduction}

Dens invaginatus, also known as dens in dente, dilated composite odontoma, or deep foramen caecum, is a developmental anomaly caused by an invagination in the surface of a tooth crown before calcification has occurred (1). Any teeth in the maxillary and mandibular arch may be affected, but maxillary lateral incisors are the most commonly observed teeth that are affected (2). Additionally, it has a frequency of 0.04 to $10 \%$ in the general population. The variation is probably due to geographical differences and different diagnostic criteria and/or investigation methods (1).

External forces on the tooth germ during development such as adjacent tooth germs, trauma, and infection, focal growth retardation on the tooth bud, focal growth acceleration on the tooth bud, and restriction of the dental arch on the enamel organ are the causal elements for the etiology of invaginated teeth (3). Dens invaginatus is known to be associated with other dental anomalies such as gemination, microdontia, macrodontia, absence of permanent tooth germs, taurodontism, supernumerary tooth, and dentinogenesis imperfect (4). The occurrence of apical root resorption of teeth with dens invaginatus during orthodontic treatment is also a well known adverse effect due to the local over compression of the periodontal ligament (5). The pulp in the invaginated canals is predisposed to infection resulting in apical breakdown. This apical breakdown may be aggravated by orthodontic forces (6).

Different classifications have been suggested to determine dens invaginatus. The most commonly used classification was described by Oehlers (7), who classified dens invaginatus into three groups according to the depth of the penetration and communication with periapical tissue or periodontal ligament: Type 1 . The invagination is confined to the crown of the tooth; Type II. The invagination extends apically beyond the cementoenamel junction but remains confined within the root as a blind sac which may communicate with the pulp; Type III. The invagination also extends beyond the cementoenamel junction, but there is no usually communication with the pulp. Additionally, a periapical or periodontal foramen is present.

There are limited studies reporting the prevalence of dens invaginatus in the literature. Therefore, the purpose of this study was to assess the prevalence of dens invaginatus in anterior teeth and to classify the type of dens invaginatus in a sample of Turkish population. This will provide the dental practitioner with information about the types of the teeth which are more likely to exhibit technical difficulties associated with the endodontic treatment of such teeth.

\section{Material and Methods}

A retrospective study was performed using full-mouth periapical and panoramic radiographs of 1138 patients ranging in age from 12 to 51 subjected to Faculty of Dentistry at the University of Ataturk (Erzurum, Turkey) between 2005 and 2008. 126 subjects with incomplete records, periapical and panoramic radiographs of poor quality were excluded. A total number of 1012 good-quality films were examined (471 females and 541 males).

Maxillary and mandibular anterior teeth were evaluated on periapical and panoramic radiographs in order to determine the presence and classification of dens invaginatus according to the classification of Oehlers (7). All radiographs were examined by investigators independently in a dark room using an X-ray viewer (Illuminator 5000, RP Beard Ltd, London UK). Initially, each radiograph was assessed separately, then a final evaluation was done together, and a combined decision was made to determine whether the tooth had dens invaginatus or not. In addition, 100 radiographs were selected at random and reevaluated by the first author 6 weeks after the first evaluation. Intra- and interexaminer reproducibility was found to be 96 and $90 \%$, respectively. Statistical evaluation of the presence of dens invaginatus related to gender was performed by the Pearson chi-squared test.

\section{Results}

Dens invaginatus was observed in 13 out of 1012 subjects, with a frequency of $1.3 \%$.The distribution of the dens invaginatus according to the gender of the subjects is shown in table 1 . Males and females were equally affected by dens invaginatus $(\mathrm{P}=0.98)$.

The distribution of the teeth with dens invaginatus is presented in table 2. 5983 maxillary and 5814 mandibular teeth were examined for the presence of dens invaginatus. The anomaly was detected in only maxillary lateral incisors (16 out of the 2011 maxillary lateral

Table 1. The distribution of the subjects with dens invaginatus.

\begin{tabular}{|l|c|c|c|c|}
\hline & Female (\%) & Male (\%) & N (\%) & P value \\
\hline $\begin{array}{l}\text { Subjects with dens } \\
\text { invaginatus }\end{array}$ & $6(1.3)$ & $7(1.3)$ & $13(1.3)$ & \\
\cline { 1 - 4 } No dens invaginatus & 465 & 534 & 999 & \multirow{2}{*}{0.98} \\
\cline { 1 - 3 } Total & 471 & 541 & 1012 & \\
\cline { 1 - 3 } & & & & \\
\hline
\end{tabular}


Table 2. The distribution of the teeth with dens invaginatus.

\begin{tabular}{|c|c|c|c|c|c|}
\hline & & & $\begin{array}{c}\text { No. of teeth } \\
\text { examined }\end{array}$ & $\begin{array}{l}\text { No. of teeth with } \\
\text { dens invaginatus }\end{array}$ & $\begin{array}{c}\text { Prevalence } \\
(\%)\end{array}$ \\
\hline \multirow{8}{*}{ Tooth type } & \multirow{4}{*}{ Maxillary } & Central incisor & 2021 & 0 & 0.0 \\
\hline & & Lateral incisor & 2011 & 16 & 0.8 \\
\hline & & Canine & 1951 & 0 & 0.0 \\
\hline & & Subtotal & 5983 & 16 & 0.3 \\
\hline & \multirow{4}{*}{ Mandibular } & Central incisor & 1859 & 0 & 0.0 \\
\hline & & Lateral incisor & 1987 & 0 & 0.0 \\
\hline & & Canine & 1968 & 0 & 0.0 \\
\hline & & Subtotal & 5814 & 0 & 0.0 \\
\hline \multicolumn{3}{|c|}{ Total } & 11797 & 16 & 0.1 \\
\hline & & & & $\begin{array}{l}\text { No. of teeth with } \\
\text { dens invaginatus }\end{array}$ & $\begin{array}{l}\text { Prevalence } \\
\quad(\%)\end{array}$ \\
\hline \multirow{4}{*}{\multicolumn{3}{|c|}{ Type of dens invaginatus }} & Type I & 13 & 81.25 \\
\hline & & & Type II & 1 & 6.25 \\
\hline & & & Type III & 2 & 12.5 \\
\hline & & & Total & 16 & 100 \\
\hline
\end{tabular}

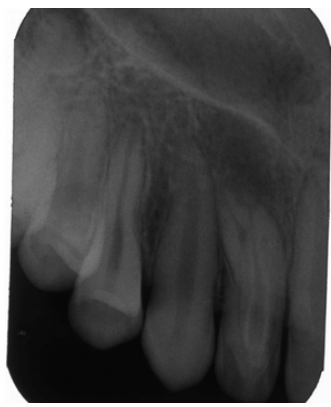

Fig. 1. Preoperative periapical radiograph showing the type III dens invaginatus and periapical lesion in the maxillary right lateral incisor.

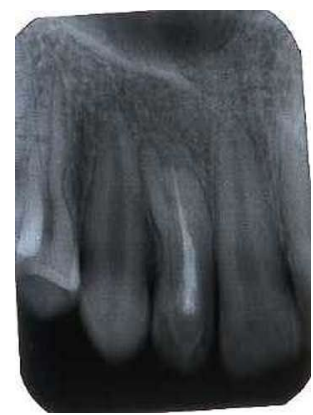

Fig. 2. Periapical radiograph showing 24 months radiographic follow-up of the invaginated lateral without any signs of pathosis.

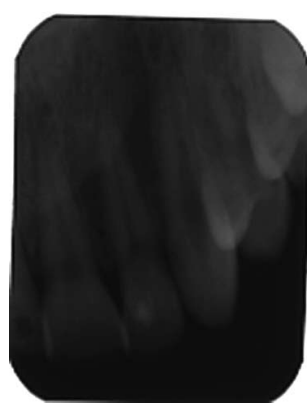

Fig. 3. Periapical radiograph showing the type I dens invaginatus in the maxillary left lateral incisor. incisors). The most commonly observed type of dens invaginatus was type I $(81.25 \%)$, followed by type III $(12.5 \%)$ while $6.25 \%$ of the teeth had type II dens invaginatus. It was mostly seen unilaterally (10 out of 13 subjects), three subjects were observed with bilateral type I dens invaginatus. There were no periapical lesions in teeth with types I and II, whereas both of the subjects with type III had apical periodontitis at the time of referral (Fig. 1, 2 and 3). No associated systemic diseases and syndromes were detected.

\section{Discussion}

The reported prevalence of the teeth affected by dens invaginatus is between $0.3 \%$ (8) and $10 \%$ (9), with the problem in $0.25 \%$ (10) to $26.1 \%$ (11) of the subjects examined. The wide variation in reported prevalence may be explained by the different cohorts studied, geographical differences and different diagnostic criteria and/or investigation methods $(9,11)$. In the present study, dens invaginatus of the anterior teeth was observed in 13 out of the 1012 subjects examined with a prevalence of $1.3 \%$ and in 16 out of the $2011(0.8 \%)$ maxillary lateral incisors examined. The result showing the prevalence of subjects with dens invaginatus is higher than the data reported by Ezoddini et al. (12), Poyton and Morgan (10) who reported the prevalence being $0.8 \%$ and $0.25 \%$, respectively. Additionally, Boyne (8) assessed 1000 maxillary lateral incisors and the prevalence of teeth with dens invaginatus was found to be $0.3 \%$. In the present 
study, no dens invaginatus were observed in the mandibular anterior teeth, and maxillary central incisors and canines examined. This result is consistent with the results of Hamasha and Alomari (13), who reported no dens invaginatus in the maxillary central incisors and mandibular anterior teeth. Additionally, Kirzioğlu and Ceyhan (14) did not find any dens invaginatus in the mandibular anterior teeth.

Oehlers' system is based on a two dimensional radiographic image and as such may underestimate the true extent and complexity of the invagination. However, despite its limitations it makes a distinction between complete (type III) and incomplete (types I and II) invaginations which is important as the management of each is potentially different. As such, this system may be more valuable from a clinical perspective than more complex classifications (15). Using the classification of Oehlers, the prevalence of each type of dens invaginatus was reported with type I being the most common (79\%), while type II (15\%) and III (5\%) (1). Additionally, Alani and Bishop (15) reported $79 \%$ of the teeth with dens invaginatus being type I. In the present study, type I was the most common type of dens invaginatus with a prevalence of $81.25 \%$.

The appearance of the symmetric dens invaginatus was considered to be a common finding by some authors. On the other hand, it has been indicated that the bilateral dens invaginatus may be related with other dental anomalies such as microdontia, gemination, fusion, and taurodontism $(13,14)$. In the present study, the symmetric dens invaginatus in the subjects was found to be $23.1 \%$. Furthermore, no other dental anomalies associated with the bilateral dens invaginatus.

There is a wide range of treatment choices for invaginated teeth. Function and esthetics, type of invagination, configuration of the root canal system, prosthetic and orthodontic treatment need, time constrains, economic and psychological considerations are some factors for the choice of the treatment. Extraction should be indicated as a last choice of treatment only in teeth with severe anatomic irregularities and in supernumerary teeth that cannot be treated non-surgically or apical surgery (2). In this study, two subjects with type III dens invaginatus had periapical pathosis at the time of referral and one tooth was treated with nonsurgical root canal treatment (Fig. 2), however, one was extracted due to the failure of the root canal treatment. Finally, the anomaly was detected in only maxillary lateral incisors with no gender difference and the most commonly observed type of dens invaginatus was type I (81.25\%).

\section{References}

1. Ridell K, Mejàre I, Matsson L. Dens invaginatus: a retrospective study of prophylactic invagination treatment. Int J Paediatr Dent. 2001;11:92-7.

2. de Sousa SM, Bramante CM. Dens invaginatus: treatment choices. Endod Dent Traumatol. 1998;14:152-8.

3. Chen YH, Tseng CC, Harn WM. Dens invaginatus. Review of formation and morphology with 2 case reports. Oral Surg Oral Med Oral Pathol Oral Radiol Endod. 1998;86:347-52.

4. Sedano HO, Ocampo-Acosta F, Naranjo-Corona RI, Torres-Arellano ME. Multiple dens invaginatus, mulberry molar and conical teeth. Case report and genetic considerations. Med Oral Patol Oral Cir Bucal. 2009;14:E69-72.

5. Bender IB, Byers MR, Mori K. Periapical replacement resorption of permanent, vital, endodontically treated incisors after orthodontic movement: report of two cases. J Endod. 1997;23:768-73.

6. Fristad I, Molven O. Root resorption and apical breakdown during orthodontic treatment of a maxillary lateral incisor with dens invaginatus. Endod Dent Traumatol. 1998;14:241-4.

7. Oehlers FA. Dens invaginatus (dilated composite odontome). I. Variations of the invagination process and associated anterior crown forms. Oral Surg Oral Med Oral Pathol. 1957;10:1204-18.

8. Boyne PJ. Dens in dente: report of three cases. J Am Dent Assoc. 1952;45:208-9.

9. Ruprecht A, Sastry KA, Batniji S, Lambourne A. The clinical significance of dental invagination. J Pedod. 1987;11:176-81.

10. Poyton HG, Morgan GA. Dens in dente. Dent Radiogr Photogr. 1966;39:27-33.

11. Thongudomporn U, Freer TJ. Prevalence of dental anomalies in orthodontic patients. Aust Dent J. 1998;43:395-8.

12. Ezoddini AF, Sheikhha MH, Ahmadi H. Prevalence of dental developmental anomalies: a radiographic study. Community Dent Health. 2007;24:140-4.

13. Hamasha AA, Alomari QD. Prevalence of dens invaginatus in Jordanian adults. Int Endod J. 2004;37:307-10.

14. Kirzioğlu Z, Ceyhan D. The prevalence of anterior teeth with dens invaginatus in the western Mediterranean region of Turkey. Int Endod J. 2009;42:727-34.

15. Alani A, Bishop K. Dens invaginatus. Part 1: classification, prevalence and aetiology. Int Endod J. 2008;41:1123-36. 